\title{
Environmental Interfaces in Teaching Economic Statistics
}

\author{
Celso Campos, ${ }^{1, *}$, Maria Lucia Wodewotzki ${ }^{2}$, Otavio Jacobini ${ }^{3}$, Denise Ferreira ${ }^{3}$ \\ ${ }^{1}$ Faculty of Economics and Administration, Pontifical Catholic University of São Paulo, Brazil \\ ${ }^{2}$ Institute of Geosciences and Exact Sciences, Sao Paulo State University, Brazil \\ ${ }^{3}$ Faculty of Engineering, Pontifical Catholic University of Campinas, Brazil
}

Copyright (C) 2016 by authors, all rights reserved. Authors agree that this article remains permanently open access under the terms of the Creative Commons Attribution License 4.0 International License

\begin{abstract}
The objective of this article is, based on the Critical Statistics Education assumptions, to value some environmental interfaces in teaching Statistics by modeling projects. Due to this, we present a practical case, one in which we address an environmental issue, placed in the context of the teaching of index numbers, within the Statistics discipline in an undergraduate course in Economic Sciences. In this project, we discuss the Human Development Index (HDI) and we propose the creation of an environmental index in order to evaluate the countries concern level in following some ecological and/or preservation practices.
\end{abstract}

Keywords Statistics Education, Critical Education, Critical Statistics Education, Mathematical Modeling

\section{Introduction}

Political awareness and the discussion of social issues related to student's reality are the main goals of Critical Education at any schooling level. In our view, as in the opinion of the main organizers of this theory (Freire, Giroux, Skovsmose, etc), such a goal can be pursued regardless of the syllabus of a discipline. We understand that educators can build adaptations to embrace themes that facilitate discussion of social-political issues, which are relevant to the student's reality. Nevertheless, it seems important to point out that to do a Critical Education pedagogy does not mean to search for methods or rules, as Giroux[1] said, "Educators should dissuade individuals who reduce teaching to the implementation of methods from entering the teaching profession" (p. 8).

\section{Theoretical Framework}

Critical Statistics Education, as presented by Campos[2], by connecting the fundamentals of Statistics Education and Critical Education shows, through mathematical modeling projects, the possibilities of integration and combination of objectives among these pedagogical approaches.

In this context, we present a fragment of the theoretical framework from Critical Statistics Education and show, through a mathematical modeling project, how it is possible to achieve positive results within this integration.

\subsection{Critical Education}

As a development of critical thinking, Critical Education has emerged in opposition to traditionalism in the educational system, and its foundation can be credited mainly to Jurgen Habermas, in Germany, and Paulo Freire, in Latin America, among others.

D'Ambrosio[3] emphasized that education should enable the students to learn and use communicative and analytical instruments, which are essential for them to exercise all rights and duties inherent to citizenship. According to him [4], the major challenge of education is to promote citizenship and creativity.

The Brazilian educator Freire[5,6] outlined the bases of a true democratic pedagogy that fights authoritarian relations and that founds its principles in an essential task. His work was marked by the special conditions of Latin American society at the time (60's and 70's), but his educational effort certainly is valid in other areas and in other time.

Freire's work, which proposes emancipatory ways of knowledge, has inspired Giroux[1], who extended the idea of democratization and politicization of education, within a vision of the teacher as a transformative intellectual. "Central to the category of transformative intellectual is the necessity of making the pedagogical more political and the political more pedagogical" (p. 127). In such a perspective "critical reflection and action become part of a fundamental social project to help students develop a deep and abiding faith in the struggle to overcome economic, political and social injustices, and to further humanize themselves as part of this struggle" (ibid., p. 127).

Skovsmose[7,8], in turn, incorporated these concepts and progressed in the development of Critical Education. The relationship between teacher and students, as for him, is of 
fundamental importance. Breaks down the figure of the knowledge-owner-teacher and takes effect the presence of the one who teaches and is taught in a dialectical relationship with the students, who become co-responsible for an educational process in which all grow. He [8] stated, "The ideas concerning the dialogue and the student-teacher relationship are developed from the general point of view that education must belong to a process of democratization" (p. 350).

Skovsmose considers that the first important aspect of Critical Education is the involvement of the students in the control of the educational processes, where both students and teachers are attributed a critical competence. According to him, another important aspect of Critical Education is the problem orientation of the teaching-learning process. Thus, he [8] stated, "it is essential that the problems have to do with fundamental social situations and conflicts, and it is important that the students simultaneously can recognize problems as their own problems" (p. 353). Centered around the democracy question, Skovsmose has worked towards a Critical Mathematics Education, in which working with modeling projects are valued.

\subsection{Statistics Education}

Mainly developed since the 1990s, Statistics Education was conceived in an unease context, trying to question and reflect over problems related with the teaching and learning of this discipline. This educational perspective was ignited by the difficulties that students have in thinking or reasoning statistically even when they show calculation skills. Seeking to differentiate the pedagogical problems presented by Statistics from those presented by the teaching of Mathematics, several authors, such as Gal, Chance, Garfield and Ben-Zvi, among others, converged on the idea that the teaching of Statistics should focus on the development of three specific skills: statistical thinking, statistical reasoning, and statistical literacy.

Statistical literacy has been well characterized by Gal[9], who emphasized two interrelated components:

a) people's ability to interpret and critically evaluate statistical information, arguments relating to data from research and stochastic phenomena found in different contexts;

b) people's ability to discuss or communicate their reactions to this statistical information, along with their interpretations, opinions, and understandings.

In turn, statistical thinking is linked to the idea of globally evaluating the statistical problem, understanding how and why statistical analyses are important. Thus, statistical thinking is related to the ability to identify statistical concepts involved in the investigations and problems dealt with, including the nature of data variability, uncertainty, how and when to properly use the methods of analysis and estimation, etc. According to Chance[10], this capacity provides the student to have the ability to explore the data in order to extrapolate what is given in the texts and to generate new questions beyond those indicated in the research

The way in which people reason with statistical concepts composes what is generally called statistical reasoning. According to Garfield[11], to reason statistically means doing appropriate interpretations of a certain data set, to correctly represent or summarize the data, to make connections between the concepts involved in a problem, or to combine ideas involving variability, uncertainty, and probability. The development of statistical reasoning should lead the student to be able to understand, interpret, and explain a real statistical data based process. Ben- Zvi[12] emphasized the importance of this capability and stated that all citizens should have it and that it should be a standard ingredient in education.

\subsection{Critical Statistics Education}

Mainly in Campos[2] and in Campos et al.[13], we have made an approach of Critical Education with Statistics Education, thus composing what we called Critical Statistics Education.

In order to develop the competences from Statistics Education in students, Campos[2] suggests:

- work with real data and relate it to the context in which it is involved;

- encourage students to interpret, explain, criticize, justify, and evaluate the results, preferably working in groups, discussing and sharing opinions.

For to address the major aspects from Critical Education, Campos et al.[13] suggest:

- problematize teaching, work on Statistics through contextualized projects within a reality consistent with the student's;

- promote debates and dialogues among students and between them and the teacher, assuming a democratic pedagogical attitude;

- thematize the teaching by prioritizing activities that enable the discussion of important social and political issues;

- use technology in teaching, valuing skills of instrumental character;

- adopt a flexible pace for developing the themes;

- discuss the curriculum and the pedagogical structure adopted.

By adopting these actions in the educational process, we will be practicing a Critical Statistics Education that goes against the traditional teaching model.

\subsection{Mathematical Modeling}

The approach of Statistics with Mathematics enhance the possibility to use some aspects from mathematics education in the design and analysis of some statistical activities in classroom. In this context we have defended [14] that working through mathematical modeling projects comprises an appropriate pedagogical strategy to carry out Critical 
Statistics Education, as it consists in an efficient way to articulate theory and practice and favors the breakup of arbitrary boundaries between disciplines, allowing a broader and more effective scope.

Modeling construction or the presence of mathematical modeling in the context of mathematics education arises mainly in situations that aim to represent and mathematically study a problem that comes from the real world and the solution should allow its analysis, reflection, awareness, discussion and validation.

We understand that mathematical modeling becomes consistent with the assumptions of Statistics Education as it combines the idea of learning Statistics through study, research, analysis, interpretation, criticism and discussion of some real situations, preferably originated from a reality consistent to the student's.

In this way, Statistics and reality can be connected through modeling activities. This interactive connection can be made by using known statistical procedures, in order to study, analyze, explain and predict situations arising from reality.

Thus, modelling can be a way to amplify the interest for statistical content among students to the extent that they have the opportunity to study, through research, problem situations that have practical application and value their critical sense.

\section{Methods}

\subsection{Environment Description}

In a Statistics discipline, taught in an undergraduate course on Economic Sciences by the first author of this paper, held in a private university from São Paulo - Brazil, one of the program contents is Economic Indices. This topic includes index numbers and others socioeconomic indices, such as Gross National Income per capita (GNIpc), infant mortality, unemployment index, life expectancy, etc. In this context, we have approached the Human Development Index (HDI), which is calculated by United Nations or, more specifically, by the United Nations Development Programme (UNDP).

HDI is supposed to emphasize that people and their capabilities should be the ultimate criteria for assessing the development of a country. As for this, the HDI should also be used to question national political choices and stimulate debates about government's priorities.

In order to achieve this goal, the HDI is a summary measure of achievement in some key dimensions of human development: a long and healthy life, access to knowledge and have a decent standard of living [15].

Discussing the wideness of this index, we have criticized the fact that it does not include indicators which could evaluate questions like religion freedom, communication liberty, human security, empowerment and democratic govern choices. The students pointed out the fact that HDI also does not include an environmental index, which could measure the nature preservation level of a country. As this is a controversial subject and generates much debate, we proposed and invited the students to carry out an activity related to this theme, organizing groups, and selecting topics for each group to make a report and prepare a presentation.

\subsection{Subject Framework}

The HDI's health dimension is assessed by life expectancy at birth and is calculated by the United Nations Department of Economic and Social Affairs (UNDESA). The education dimension has two components: years of schooling for adults aged 25 years and expected years of schooling for children of school entering age. These indicators are produced by UNESCO Institute for Statistics. The two indices are combined into an education index using arithmetic mean. The standard of living dimension is measured by the GNIpc, respecting the purchasing power parity (PPP) methodology, calculated by World Bank (up to 2012) and IMF (2013).

Minimum and maximum values (goalposts) are set for each sub-index in order to transform the indicators expressed in different units into indices between 0 and 1 . These goalposts act as the 'natural zeroes' and 'aspirational goals', respectively, from which component indicators are standardized. UNDP has set the goalposts at the following values:

Table 1. Goalposts for HDI sub-indices calculations

\begin{tabular}{|c|c|c|c|}
\hline Dimension & Indicator & Minimum & Maximum \\
\hline Health & Life expectancy (years) & 20 & 85 \\
\hline \multirow{2}{*}{ Education } & $\begin{array}{c}\text { Expected years of } \\
\text { schooling }\end{array}$ & 0 & 18 \\
\cline { 2 - 4 } & Mean years of schooling & 0 & 15 \\
\hline $\begin{array}{c}\text { Standard of } \\
\text { living }\end{array}$ & $\begin{array}{c}\text { Gross national income per } \\
\text { capita (PPP 2011 USD) }\end{array}$ & 100 & 75,000 \\
\hline
\end{tabular}

Source: [16], p.2

The basic formula for each sub-index is:

$$
I_{i}=\frac{X_{i}-\operatorname{MIN}\left(X_{i}\right)}{\operatorname{MAX}(X i)-\operatorname{MIN}\left(X_{i}\right)}
$$

where:

$\mathrm{I}_{\mathrm{i}}=$ index of the referred variable

$\mathrm{X}_{\mathrm{i}}=$ observed value of the variable

$\operatorname{MIN}\left(\mathrm{X}_{\mathrm{i}}\right)$ and $\operatorname{MAX}\left(\mathrm{X}_{\mathrm{i}}\right)$ are the lowest and highest values that variable $\mathrm{X}$ can attain, respectively, according to table 1 .

For the income index, the natural logarithm of the actual, minimum and maximum values is used ${ }^{1}$.

Thus, HDI is given by the geometric mean of the normalized indices for each of these three dimension:

$$
H D I=\left(I_{\text {health }} \cdot I_{\text {education }} \cdot I_{\text {income }}\right)^{1 / 3}
$$

There are others aggregated indices calculated by UNDP, which are: Inequality-adjusted Human Development Index, Gender Development Index, Gender Inequality Index and

1 For more details about these calculations, see UNDP (2014b) at http:/hdr.undp.org/en/2014-report/download 
Multidimensional Poverty Index [16], but none of them is related to environmental issues.

\subsection{Project Development}

After students have been organized into groups (by themselves), we have discussed several topics that they could study and research. Therefore, they selected the following topics:

- Recycling and reuse: economic impacts

- Sustainable cities

- Economic consequences of global warming

- Socio-environmental responsibility in enterprises

- Green economy

- Environmental index

Each group became responsible for one topic. The first five topics were to be presented 14 days from that class. The last topic would be presented one week after that. Thus, the first five presentations should help the last group to construct the environmental index. On the other hand, every group were assigned to make a report on the subject researched.

The five first presentations occurred in the expected date. Groups made power-point presentations and everyone discussed all topics with great enthusiasm. Although the topics did not refer to statistical contents, all groups presented real data summarized in tables and charts, which were inserted in the presentations as well as in the reports. As they were not used to make reports, they had revealed some difficulties in mixing text and data, but with a little help from the teacher, it was no problem at all.

Later, the last group have asked for teacher's help in order to build a good index. One meeting with the students was held outside class schedule and some doubts were solved at the reunion and by e-mail.

At the expected date, the last topic was presented. Many discussions surrounded the presentation and all students wanted to express their points of view. The index was proposed using the HDI formula (1) and several sub-indices were suggested:

$I_{1}$ ) sewer treatment index: it measure the percentage of treated sewage released into the environment in relation to the total production of sewer;

$\mathrm{I}_{2}$ ) launching rate of gases that cause greenhouse effect;

$I_{3}$ ) atmospheric pollution index of the great cities;

$\mathrm{I}_{4}$ ) native vegetal covering preservation index;

$\mathrm{I}_{5}$ ) beaches bathing index, given by the improper beach percentage for the bath due to pollution, in relation to the total number of beaches;

$I_{6}$ ) recycling index, given by the percentage of effectively recycled materials;

$\mathrm{I}_{7}$ ) energy index, given by the percentage of the total energy matrix that comes from clean and/or renewable sources;

$I_{8}$ ) animal species preservation index, given by the number of extinguishing threatened animal species of the local fauna.

The aggregated environmental preservation index should not be calculated by the formula (2), but through a simple arithmetic mean of the sub-indices, normalized as the HDI formula (1) proposes. The country would be more engaged in environmental preservation as the result gets closer to 1 .

There was a problem pointed out by the teacher. Some sub-index get higher grade as the country environment preservation get worst $\left(\mathrm{I}_{2}, \mathrm{I}_{3}, \mathrm{I}_{5}\right.$, and $\left.\mathrm{I}_{8}\right)$. In those cases, the sub-index should be obtained after been subtracted by 1 . The group understood the teacher explanation and made the appropriated corrections.

In the following debates, students seems to be infuriated with the fact that an environmental preservation index officially does not exist and they discussed divulging forms to lead this information to the general population.

It was not possible to estimate the index for the country, but several questions have raised from the debates. Who would not be interested in calculating this kind of index? Would some developed countries be downgraded if this index becomes part of HDI?

\section{Analysis}

\subsection{Due to Statistical Content}

In this modeling project, the statistical content worked was an index calculation. Nevertheless, the first five groups have worked on data summarizing and representations, using appropriated tables and graphics. Data interpretation and analysis were also carried out. Students realized the importance of using technology to access reliable results, as data were obtained via internet, the graphs and tables were made with the help from Excel spreadsheet and the presentation have used Power Point slides . Additionally they were able to note the importance of working with real data.

As for the last group, they had deepened on index subject and had detailed the calculation methodology. By creating a simple and objective index, they had involved all students in this matter and had contributed for all of them to experiment the knowledge related to this kind of calculation.

\subsection{Due to Statistical Competences}

Relating to the three capacities mentioned by the Statistical Education's theoretical framework, we observed that working with real situations involved in the index calculation allowed students to have a global view of the problem. Students had been able to perceive the difficulties that surround the complexity of this index and had followed some statistical tools used in its determination. We understand that this work tends to help the development of statistical thinking and statistical reasoning on data and measures.

The interpretations that students made about the statistical tools used for index calculations can be seen as an ability to explore the content, extrapolating what is prescribed in the 
books. In line with this, as pointed out by Chance[10], we can say that students progressed in the development of statistical thinking.

As for statistical reasoning, Garfield[11] suggested that its development should lead students to be able to understand, interpret and explain a real statistical process. This was completely done by the students, as they focused the idea of creating a new index and were able to construct meanings for the formulas, in a non-trivial way, and explained all the process to the class.

Due to literacy, we believe that the preparation of reports, the use of statistics typical expressions and terminologies, the elaboration work of the presented charts and tables, as well as the quarrels involving the environment preservation index thematic tends to assist the development of this competence.

Moreover, we mentioned Gal[9], who pointed out that statistical literacy emerges when students are able to interpret and critically evaluate statistical information and arguments related to researched data. He also highlighted that literacy appears when people discuss or communicate their reactions to such statistical data, their interpretations, opinions and understandings.

Thus, we believe that our students achieved this goal as they showed, discussed and communicated their interpretations, critical evaluations and understandings of the index calculations.

\subsection{Due to Critical Education and Critical Statistics Education}

According to Giroux[1], Critical Education is not a method, so it is not a question of measuring its deepness or follow some steps. Nevertheless, we believe that in many ways the Critical Education principles were present in this project. In the presentations and discussions, students were faced to the environment degradation problem, its political implications and its consequences. We were able to experiment the emergence of a sense of outrage at the attitudes of people and governments facing a problem that affects everyone, rich or poor. The debates have shown a repudiation and revolt feeling to the indifference posture of the authorities, even from UN. Moreover, the pupils had argued forms of fighting the ambient degradation problem and the possible actions towards it, raising awareness of the importance of environmental preservation.

Besides this aspect, it is important to mention the democratic way in which we developed this project. The theme emerged from the students; they chose the topics and organized themselves into groups. The teacher acted like a mediator, taking position on the discussed subjects and giving voice to the students, encouraging the debates.

As for Critical Statistics Education, we perceive that throughout the project, we had been in the path traced for the theoretical considerations foreseen by Campos, Wodewotzki and Jacobini[13], as we followed most of the suggested attitudes for the classroom work, mentioned here: (i) We have problematized the teaching, we had worked topics related to statistics through a contextualized project, consistent to the students' reality;

(ii) We have encouraged debate and discussions among students and between them and the teacher, thus taking a democratic pedagogical position;

(iii) We have thematized the teaching and focused on activities emphasizing the debate of several important social and political issues;

(iv) We have used technology in teaching and valorized technical skills.

\section{Conclusions}

In the execution of the pedagogical activities related to the project that we described here, we had the objective of showing a possibility of insertion of Critical Statistics Education inside a content from Statistics discipline in an undergraduate course. In this context, we tried to emphasize the social political interfaces involved in the suggested thematization, that emerged from the pedagogical environment lived by the professor. Our interest when telling this experience was to show that the opportunities of insertion of a thematic related to social and political problems occur at several moments at a pedagogical action. We understand that it is up to the educator to take advantage of these situations in order to stimulate the critical, investigative and contester spirit of the students, which stands out when they face a social problem, which involves their reality.

We believe that, without losing focus on the statistical contents, when adopting Critical Statistics Education we can excessively enrich the pedagogical process, which gives the student the chance to better understand his/her own reality. Thus, they can find ways to carry out actions, which actually represent reactions against the unjust and sometimes immoral system in which they live. Due to this, we understand that the professor carries through a much more comprehensive role and makes education more meaningful, more interesting and more genuine.

\section{REFERENCES}

[1] H. Giroux. Teachers as intellectuals: toward a critical pedagogy of learning, Bergin \& Garvey, Westport, 1988.

[2] C. R. Campos. A Educação Estatística: uma investigação acerca dos aspectos relevantes à didática da estatística em cursos de graduação, Doctoral thesis, UNESP-IGCE, Rio Claro, 2007.

[3] U. D’Ambrosio. Etnomatemática: elo entre tradições e modernidade, Autêntica, Belo Horizonte, 2002.

[4] U. D'Ambrosio. Armadilha da mesmice em Educação Matemática, UNESP-IGCE, Rio Claro, BOLEMA, n. 24, pp. 
95-109, 2005.

[5] P. Freire. Education for critical consciousness, Continuum, New York, 1973.

[6] P. Freire. Pedagogy of the oppressed, Continuum, New York, 2000.

[7] O. Skovsmose. An invitation to critical mathematics education, Sense Publishers, Rotterdam, 2011.

[8] O. Skovsmose. Critique as uncertainty, Information Age Publishing, Charlotte, 2014.

[9] I. Gal. Statistical Literacy: Meanings, Components, Responsibilities., D. Ben-Zvi \& J. Garfield, The challenge of developing statistical literacy, reasoning and thinking, pp. 47-78, Kluwer, Dordrecht, 2004.

[10] B. L. Chance. Components of Statistical Thinking and Implications for Instruction and Assessment, ASA, Journal of Statistics Education, Vol. 10, n. 3, 2002. (http://www.amstat.org/publications/jse/v10n3/chance.html)

[11] J. Garfield. The challenge of developing statistical reasoning,
ASA, Journal of Statistics Education, Vol. 10, n. 3, 2002. (http://www.amstat.org/publications/jse/v10n3/chance.html)

[12] D. Ben-Zvi, Research on developing statistical reasoning: reflections, lessons learned, and challenges, ICME 11 Proceedings (International Congress on Mathematical Education), Monterrey, 2008.

(http://icme11.org/node/1530.html)

[13] C. R. Campos, M. L. L. Wodewotzki \& O. R. Jacobini. Educação Estatística: teoria e prática em ambientes de modelagem matemática, Autêntica, Belo Horizonte, 2011.

[14] C. R. Campos, D. H. L. Ferreira, O. R. Jacobini \& M. L. L. Wodewotzki, Mathematical modelling in the teaching of statistics in undergraduate courses. G. A. Stillman, W. Blum \& M. S. Biembengut, Mathematical modelling in education research and practice: cultural, social and cognitive influences, pp. 501-512, Springer, New York, 2015.

[15] UNDP. Human development report: reducing vulnerabilities and building resilience, UNDP, New York, 2014.

[16] UNDP. Human development report: technical notes, UNDP, New York, 2014. 